\title{
Transorbital endoscopic assisted management of intraorbital lesions: lessons learned from our first 9 cases* $^{*}$
}

\author{
lacopo Dallan 1,2, Paolo Castelnuovo 2,3, Mario Turri-Zanoni2,3, Giacomo \\ Fiacchini', Davide Locatelli ${ }^{2,4}$, Paolo Battagliaa ${ }^{2,3}$, Stefano Sellari-Franceschini ${ }^{3}$ \\ ' First Otorhinolaryngologic Unit, Azienda Ospedaliero-Universitaria Pisana, Pisa, Italy \\ ${ }^{2}$ Head and Neck Surgery and Forensic Dissection Research center (HNSandFDRc), University of Insubria, Varese, Italy \\ ${ }^{3}$ Unit of Otorhinolaryngology, Department of Biotechnology and Life Sciences (DBSV), University of Insubria, \\ Azienda Ospedaliero-Universitaria Ospedale di Circolo e Fondazione Macchi, Varese, Italy \\ ${ }^{4}$ Unit of Neurosurgery, Department of Biotechnology and Life Sciences (DBSV), University of Insubria, \\ Azienda Ospedaliero-Universitaria Ospedale di Circolo e Fondazione Macchi, Varese, Italy
}

Rhinology 54: 247-253, 2016

DOI:10.4193/Rhino15.237

*Received for publication:

August 20, 2015

Accepted: January 14, 2016

\begin{abstract}
Background: The management of intraorbital lesions is challenging and it is strongly dependent to their nature, position and biological behaviour. Traditionally, the superior and lateral compartments of the orbit are addressed via lateral orbitotomy or transcranial approaches. Herein we present our preliminary experience in the management of selected supero-lateral intraorbital lesion through an endoscopic-assisted superior-eyelid approach.
\end{abstract}

Methodology: All cases of intraorbital lesion treated in two Italian tertiary care referral centres using a superior eyelid endoscopic-assisted transorbital approach were retrospectively reviewed.

Results: Nine patients have been analysed. The aim of surgery was diagnostic in 5 cases and curative in the remaining 4 patients. Significant tissue biopsy was obtained in all the five diagnostic procedures. Complete resection was obtained in 3/4 lesions. No major intra- or postoperative complications have been observed. Mean surgical time was 68 minutes. Mean hospitalization time was 4.4 days. All patients were satisfied about the surgical procedure, as emerged by the post-operative counselling. At present, the mean follow-up time is 18 months, ranging from 11 to 25 months.

Conclusions: Our preliminary results are promising with successful functional and cosmetic outcomes and reduced morbidity for the patient. This approach should be considered as an option for selected intraorbital lesions.

Key words: skull base, orbit, endoscopic assisted surgery, intraconal, extraconal

\section{Introduction}

The management of orbital lesions is challenging and it is strongly dependent to their nature, position and biological behaviour. As a matter of fact, surgical decision greatly depends on the type and position of the lesion and on patient's symptoms and expectations. From a surgical viewpoint, different orbital regions can be reached by means of different approaches, each of them offering a specific angle of attack. Traditional orbital approaches are very effective but can be associated with a not negligible morbidity. On the other side, it is well known that for a large subset of lesions, such as lymphomas, pseudotumors and granulomatous pathologies, the role of surgery may only be limited to that of a biopsy and therefore traditional surgical procedures could be too aggressive. Notwithstanding this, the lateral orbitotomy should anyway be considered the procedure of choice for many lesions requiring definitive surgical management ${ }^{(1)}$. At the time of writing, transnasal endoscopic orbital surgery is well established for orbital decompression, orbital floor fracture repair and it is becoming a valid alternative for resection of selected intraorbital lesions, especially those placed in the medial and infero-medial compartments ${ }^{(2-4)}$. Endoscopicassisted not transnasal but transorbital approaches are quite neglected although transcutaneous orbital endoscopic surgery was pioneered and described in the early $80^{\prime} \mathrm{s}^{(5)}$. Actually very 
few data concerning this surgical option are reported in literature ${ }^{(1,6,7)}$, and the number of cases collected is really limited. Herein we present our preliminary experience with nine cases of intraorbital lesions managed via superior eyelid transorbital endoscopic-assisted approach. A careful review of the pertinent literature and extensive discussion about advantages and limits of this procedure will be also provided.

\section{Materials and methods}

All the cases of intraorbital lesion treated by means of a superior eyelid endoscopic-assisted approach have been included in this study. Both diagnostic and curative procedures were included in the present analysis. The study has been conducted in two Italian tertiary care referral centres with comprehensive experience in orbital and endoscopic skull base surgery, in line with policies approved by the local Ethical Committee. Demographic data, presenting symptoms, locations of the lesion, histologies, intra and post-operative complications, hospitalization time and subjective quality of life evaluation of the patients treated have been collected and analysed. The proptosis was estimated combining information obtained using the Hertel exophthalmometer and CT scan measurements.

The patients' Quality of Life (QoL) was assessed using the Glasgow Benefit Inventory (GBI), a retrospective generic QoL questionnaire developed by Robinson et al. ${ }^{(8)}$, which has been validated for Otorhinolaryngological surgical procedures ${ }^{\left({ }^{9}\right)}$ and recently used also for orbital surgery ${ }^{(10)}$. It is a useful tool for measuring post procedural patient-perceived benefit, because it is highly sensitive to change and is only administered post procedure. The official Italian translation was used. The questionnaire was completed during a telephone interview conducted by a member of the study team one month after the transorbital surgery. Three domains are covered by 18 items: 12 related to general improvement; 3 to social improvement; and 3 to physical improvement. Responses can be given on a 5-point Likert scale, from a large deterioration (score 1) through to a large improvement in health status (score 5). Post hoc analysis converts the results of the questionnaire to a score from -100 (maximal detriment) through zero (no change) to +100 (maximal benefit). Indications and Contraindications.

Patients were selected for transorbital endoscopic assisted surgery through a superior eyelid approach when the lesion was placed in the lateral or supero-lateral quadrants of the orbit, in the lacrimal gland region, in the retrobulbar spaces or even in the orbital apex region. Exclusion criteria included huge lesions, extensive lesions invading the cavernous sinus or the optic canal. Complex high-flow lympho-vascular malformations were also excluded.

\section{Surgical technique}

Before starting the surgical procedure, antibiotic drops are placed in the conjunctival sac. Eyelids are gently sutured in order to protect the cornea. The incision is performed in a crease of the superior eyelid. A careful dissection below the plane of the orbicularis oculi muscle is performed and care is taken in sparing the orbital septum at the beginning of the procedure (11). Once the supero-lateral aspect of the orbital rim is identified, a careful dissection between the inner surface of the orbit and the periorbita is performed in order to create enough space for working. At this point the procedure continues under endoscopic guidance. The periorbita is usually left intact until the moment to enter inside of the orbital content. An incision is then taken on the periorbital layer at the approximate depth of the lesion. Adequate and careful use of malleable retractor is necessary in order to create enough space for working. According to the position of the lesion, several anatomical structures should be identified. Among them, the lateral rectus muscle represents one of the first key anatomical elements to be identified in order to guide further steps. The lacrimal gland has to be exposed only when involved by the pathology; otherwise it is better to leave it covered by the periorbit. Once the lesion is identified, a gentle dissection with blunt and sharp instruments is performed all around. Identification of feeders and their management is adequately performed with bipolar under continuous irrigation. Adhesions to surrounding structures are carefully evaluated because critical relationship should call for a wise management and not for an "any-price" resection. During the procedure, the surgical dissection is broke up several times for some minutes in order to make the eye relaxing. For deep located lesions, the intraoperative use of a magnetic navigation system with CT and MRI fusion imaging is strongly advisable. Especially when dealing with intraconal lesions, it is of paramount importance to preserve, as much as possible, neural and vascular structures, even at the cost of partial resection, so performing a "functional oriented surgery". As a matter of fact, a given procedure will be considered minimally invasive not only for the type of surgical approach adopted but also mainly for the functional outcomes obtained ${ }^{(11)}$. Once the surgical removal of the lesion is completed, an accurate haemostasis is achieved and a small drainage is put in place. Eyelid wound suture is then performed and eye packing is placed for at least 24 hours.

\section{Results}

Nine patients represent the cohort of this study. There were 5 male and 4 female. Mean age at surgery was 48.9 years. Demographic and clinical data are summarized in Table 1. The position of the lesion in the intraconal or extraconal compartment is detailed in Table 1. Moreover, also the depth of the lesion inside the orbit, assessed by measuring the distance between the orbital rim and the deepest part of the lesion, is provided in Table 1, where the tumors have been stratified according to their location in the anterior orbital region, posterior orbital region or 
Table 1. Main demographic and clinical data of the 9 patients affected by intraorbital lesions managed through an endoscopic assisted superior eyelid transorbital approach.

\begin{tabular}{|c|c|c|c|c|c|c|c|c|c|}
\hline $\begin{array}{l}\text { Patient } \\
\text { ID }\end{array}$ & Sex & $\begin{array}{c}\text { Age } \\
\text { (years) }\end{array}$ & Side & Intraorbital location & Position & \multicolumn{2}{|r|}{$\begin{array}{l}\text { Hospitaliza- } \\
\text { tion time } \\
\text { (days) }\end{array}$} & \multicolumn{2}{|c|}{ Aim of surgery } \\
\hline 1 & $\mathrm{~F}$ & 60 & $\mathrm{R}$ & Intraconal & $\mathrm{AH}, \mathrm{PH}$ & \multicolumn{2}{|l|}{ Fever, Epilepsy } & \multicolumn{2}{|c|}{ Resection } \\
\hline 2 & $F$ & 70 & $\mathrm{~L}$ & Intra/extraconal & $\mathrm{AH}, \mathrm{PH}$ & Proptosis & 1 & \multicolumn{2}{|l|}{ Biopsy } \\
\hline 3 & M & 3 & $\mathrm{~L}$ & Extraconal & $\mathrm{AH}$ & $\begin{array}{l}\text { Fever, Orbital swelling, } \\
\text { Pain }\end{array}$ & g, & \multicolumn{2}{|l|}{ Biopsy } \\
\hline 4 & M & 39 & $\mathrm{~L}$ & Intra/extraconal & $\mathrm{AH}$ & $\begin{array}{l}\text { Proptosis, Pain, Diplo- } \\
\text { pia, Eye movements' } \\
\text { insufficiency }\end{array}$ & - & \multicolumn{2}{|l|}{ Biopsy } \\
\hline 5 & $M$ & 74 & $\mathrm{R}$ & Extraconal & $\mathrm{AH}, \mathrm{PH}$ & Proptosis, Epiphora & 1 & \multicolumn{2}{|l|}{ Biopsy } \\
\hline 6 & M & 51 & $\mathrm{~L}$ & Extraconal & $\mathrm{AH}$ & $\begin{array}{l}\text { Proptosis, Diplopia, Eye } \\
\text { movements' insuffici- } \\
\text { ency }\end{array}$ & Eye & \multicolumn{2}{|c|}{ Resection } \\
\hline 7 & M & 53 & $\mathrm{~L}$ & Extraconal & $\mathrm{AH}, \mathrm{PH}, \mathrm{OA}$ & $\begin{array}{l}\text { Proptosis, Upper eyelid } \\
\text { ptosis, Eye accomoda- } \\
\text { tion's insufficiency }\end{array}$ & lid & \multicolumn{2}{|c|}{ Resection } \\
\hline 8 & $\mathrm{~F}$ & 40 & $\mathrm{R}$ & Intra/extraconal & $\mathrm{AH}, \mathrm{PH}$ & Proptosis & 5 & \multicolumn{2}{|c|}{ Resection } \\
\hline 9 & $\mathrm{~F}$ & 50 & $\mathrm{R}$ & Extraconal & $\mathrm{PH}$ & Proptosis & 1 & \multicolumn{2}{|l|}{ Biopsy } \\
\hline $\begin{array}{l}\text { Patient } \\
\text { ID }\end{array}$ & Histolc & & \multicolumn{2}{|c|}{$\begin{array}{l}\text { Intra-operative complica- } \\
\text { tions }\end{array}$} & $\begin{array}{l}\text { Post-operative } \\
\text { complications }\end{array}$ & $\begin{array}{l}\text { Post-operative } \\
\text { treatments }\end{array}$ & $\begin{array}{l}\text { Persistence or } \\
\text { recurrence of } \\
\text { disease }\end{array}$ & $\begin{array}{l}\text { QoL } \\
\text { scores }\end{array}$ & $\begin{array}{l}\text { Follow- } \\
\text { up } \\
\text { (months) }\end{array}$ \\
\hline 1 & $\begin{array}{l}\text { Warthi } \\
\text { lacrima }\end{array}$ & $\begin{array}{l}\text { umor of the } \\
\text { and }\end{array}$ & \multicolumn{2}{|l|}{-} & - & - & - & +100 & 18 \\
\hline 2 & Psudot & r orbitae & \multicolumn{2}{|c|}{$\begin{array}{l}\text { Small damage of the } \\
\text { conjunctiva (sutured) }\end{array}$} & - & $\begin{array}{l}\text { Corticosteroid } \\
\text { therapy }\end{array}$ & - & +75 & 16 \\
\hline 3 & $\begin{array}{l}\text { Langer } \\
\text { histioc }\end{array}$ & $\begin{array}{l}\text { s cells } \\
\text { is }\end{array}$ & \multicolumn{2}{|l|}{ - } & - & Chemotherapy & - & +100 & 25 \\
\hline 4 & $\begin{array}{l}\text { Polyme } \\
\text { grade }\end{array}$ & $\begin{array}{l}\text { ous low- } \\
\text { ocarcinoma }\end{array}$ & \multicolumn{2}{|l|}{-} & 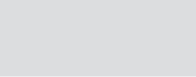 & $\begin{array}{l}\text { Surgical exente- } \\
\text { ratio orbitae }\end{array}$ & - & 0 & 19 \\
\hline 5 & Lymph & & \multicolumn{2}{|l|}{-} & - & Chemotherapy & - & +75 & 19 \\
\hline 6 & Pleom & ic adenoma & \multicolumn{2}{|l|}{-} & - & - & - & +100 & 23 \\
\hline 7 & Solitar & rous tumor & \multicolumn{2}{|c|}{$\begin{array}{l}\text { Bleeding; damage of the } \\
\text { levator palpebrae (sutured) }\end{array}$} & $\begin{array}{l}\text { Upper eyelid } \\
\text { ptosis (partially } \\
\text { solved in four } \\
\text { weeks) }\end{array}$ & - & $\begin{array}{l}\text { Persistence of } \\
\text { disease (surgi- } \\
\text { cally removed } \\
\text { with lateral } \\
\text { orbitotomy) }\end{array}$ & -25 & 16 \\
\hline 8 & Pleom & ic adenoma & \multicolumn{2}{|l|}{-} & $\begin{array}{l}\text { Upper eyelid } \\
\text { ptosis (solved } \\
\text { in two weeks) }\end{array}$ & - & - & +50 & 15 \\
\hline 9 & $\begin{array}{l}\text { Dense } \\
\text { connec }\end{array}$ & $\begin{array}{l}\text { us } \\
\text { tissue }\end{array}$ & \multicolumn{2}{|l|}{-} & - & - & - & 0 & 11 \\
\hline
\end{tabular}

F, female; $M$, male; $R$, right; L, left; $A H$, anterior half of the orbit; $\mathrm{PH}$, posterior half of the orbit; $\mathrm{OA}$, orbital apex; QoL, quality of life.

orbital apex.

The aim of surgery was curative in 4 cases (Figure 1) and diagnostic in the remaining 5 patients (Figure 2). Surgical time was comprised between 40 and 130 minutes (mean, 68 minutes). No major intra or post-operative complications (diplopia, visual im- pairment, permanent ptosis) were observed. Mean hospitalization time was 4.4 days. Significant tissue biopsy was obtained in all the five diagnostic procedures. Among the four patients scheduled for surgery with curative intent, in all but one a complete removal of the lesion was obtained. In one case of recurrent 

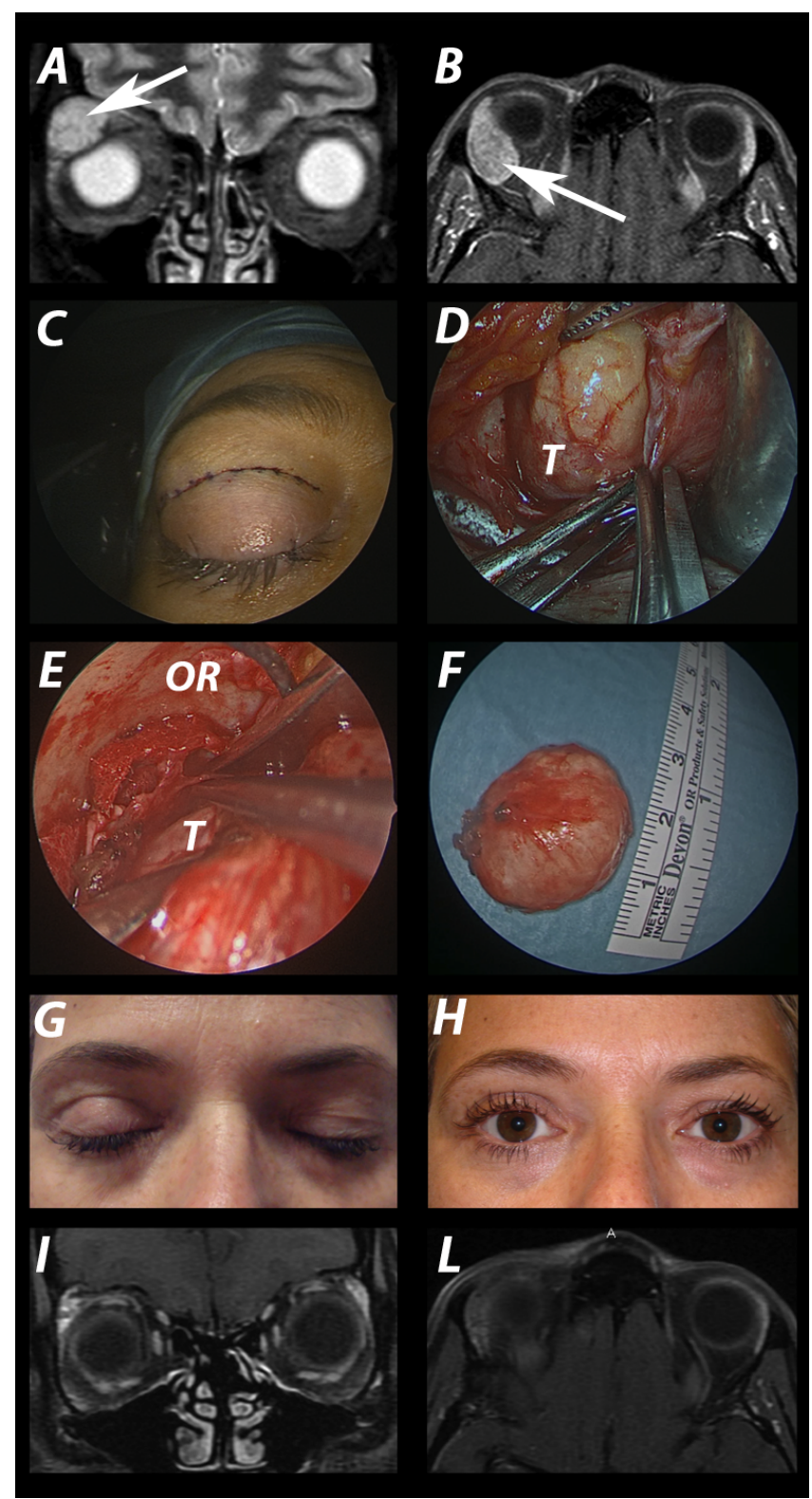

Figure 1. Pre-operative contrast-enhanced MR scan in coronal $(A)$ and axial (B) view of a right lacrimal gland pleomorphic adenoma, pointed out by white arrows (case \#9). (C) superior eyelid incision; (D) blunt dissection of the tumor; $(E)$ exposure of the orbital rim through the transorbital corridor; $(F)$ the removed lesion was sized $2.5 \mathrm{~cm}$ about. Functional and aesthetic outcomes of the right superior eyelid one month after surgery are depicted in $(\mathrm{G})$ and $(\mathrm{H})$. Post-operative contrastenhanced MR scan in coronal (I) and axial (L) view confirmed the radical resection of the intraorbital lesion. Legend: $T$, tumor; OR, orbital rim.

solitary fibrous tumor (also named hemangiopericytoma) only a partial resection was achieved due to the strict tumor adhesion with intraorbital neurovascular structures and the severe bleeding encountered during surgery. Other two patients showed a postoperative upper eyelid ptosis completely solved in a few weeks after surgery. Remarkably, the seven patients presenting

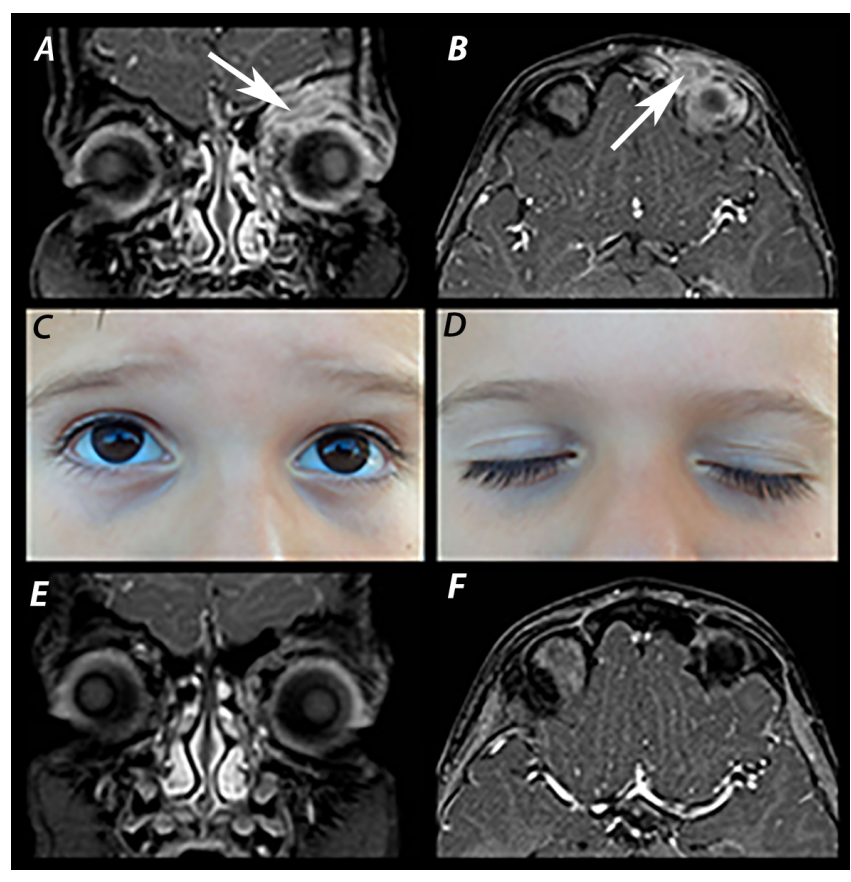

Figure 2. A 3-years old boy presented to our attention with fever, orbital swelling and pain (case \#3). The contrast-enhanced MR scan in coronal (A) and axial (B) view showed a left supraorbital lesion extending into the orbit (superior compartment). White arrows mark the lesion. The superior eyelid endoscopic assisted transorbital approach provided a direct and minimally-invasive access for tissue sampling. The final histology was compatible with single-system single site Langerhans cells histiocytosis (positive for CD1a and S100; negative for desmin and myogenin). The patient underwent chemotherapy according to the protocol $\mathrm{LCH}-\mathrm{III}$, including vinblastine and methylprednisolone. The left superior eyelid looks normal from aesthetic and functional point of view one year after surgery. The contrast-enhanced MR scan in coronal (E) and axial (F) view showed a complete response.

with pre-operative proptosis and exophthalmos obtained a complete resolution of these symptoms (mean improvement of $2.4 \mathrm{~mm}$ ). All patients were satisfied about the surgical procedure, as emerged by Quality of Life questionnaire completed one month after surgery. The total GBI scores of patients are provided in Table 1. Globally, we observed an improvement of the patient QoL (mean of the total scores, +52.7 ) in our series. At present, the mean follow-up time is 18 months, ranging from 11 to 25 months.

\section{Discussion}

Orbital lesions represent a real challenge and their management depends on several factors, including patient's expectations as well as the position, nature and biological behaviour of the lesion. Traditional external approaches, with different skin or trans-conjunctival incisions, represent an effective and sound surgical option for the management of this kind of lesions ${ }^{(12)}$. 
No need to say that the ideal approach would offer an adequate visualization of the intraorbital lesion without requiring significant manipulation of critical neurovascular orbital structures and possibly minimizing tissue handling. So, from a practical viewpoint, any surgical approach should be designed to give the most direct access to the lesion, while minimizing trauma to adjacent tissues ${ }^{(13)}$. It is obvious that each available approach presents its own advantages and limitations and it is well known that no single route is able to offer an optimal exposure in every case. As not minor consideration, when dealing with orbital tumors, we feel that the decision to surgically intervene should not imply an obligation for a radical resection at any price. So, the intraoperative finding of some unmanageable attachments should advice modifications in the surgical strategy in order to preserve vision and function.

Currently, lateral orbitotomy should be considered the workhorse in orbital tumors surgery ${ }^{(12)}$. But, especially for diagnostic purpose this procedure seems to be too aggressive. As a consequence, we strongly feel that the surgical approach should be absolutely personalized and carefully discussed with patients. On the other side, nowadays there is a strong interest toward minimally invasive procedure that means, in simple words, less discomfort and shorter hospitalization for the patients. These aspects make minimally invasive approaches significantly attractive.

However, at present, the lateral aspect of the orbital content is generally approached via transcranial routes (fronto-orbitozygomatic, fronto-temporal, supraorbital craniotomies) for orbital apex lesions ${ }^{(14)}$ and mostly with lateral orbitotomy approach for more anteriorly located lesions ${ }^{(12)}$. Very recently, a non-endoscopic transorbital approach has been proposed for extradural tumors ${ }^{(15)}$. As a matter of fact, traditional approaches to the lateral orbital content usually require at least some bony work. And obviously such procedures could be associated with non-negligible morbidity. Moreover, if the muscle detachment is additionally required in order to increase the working space, a transient or a permanent post-operative diplopia may occur. Actually, non-transnasal endoscopic assisted approaches inside and around the orbit are quite neglected, with very few exceptions $(6,7,16,17)$. Given our widespread experience in balanced orbital decompression for Graves disease ${ }^{(18)}$ as well as in endoscopic skull base surgery and transnasal intraorbital approaches ${ }^{(2-4)}$, we started to manage selected intraorbital lesions via a superior eyelid approach, under endoscopic assistance. All the patients were fully informed that in case of major intraoperative difficulties or complications we should have converted the procedure into a more traditional approach.

Based on the present experience, we feel that the superior eyelid approach provides an adequate exposure of the lateral and superior aspects of the orbital spaces, including both the extraconal and intraconal compartment, from the lacrimal gland region back to the orbital apex. Endoscopic visualization, with its magnification and angled view, permits an adequate identification of the main anatomical structures thus allowing a delicate and precise surgery. Technically speaking, multi-hands technique permits to cope with lesions according to the same surgical principles of the open approaches. In this contest it should be underlined that the role of the second and third surgeons is extremely critical in order to maintain an adequate exposure and visualization. In all our cases, when a radical resection was planned, a careful combination of blunt and sharp dissection was performed. For lacrimal gland tumors, we tried to respect the healthy part of the gland (if oncologically possible) in order to reduce the risk of post-operative dry eye. In orbital apex lesions, adhesions to the surrounding neurovascular structures, especially the ophthalmic artery and the optic nerve, can be found intra-operatively and it should be outlined that such micro-anatomical details cannot be predictable/detectable pre-operatively. Notwithstanding, functional outcomes may be greatly affected by such relationships.

Furthermore, in order to reduce possible risks associated with the site overheating owing to the presence of the endoscope, the surgical field was regularly irrigated with saline solution. Moreover, as a general consideration, achieving meticulous haemostasis is necessary in order to prevent increases in intraorbital pressure. In all patients but one treated with curative intent, a complete resection of the lesion was obtained while all the diagnostic procedures were successfully completed with the suspected tissues reached and sampled. No conversion to traditional open approaches was required in the present series. In one case of a recurrent solitary fibrous tumor (case \#7, Table 1), we experienced some difficulties in managing intraoperative bleeding and in dissecting the lesion from the surrounding structures, precluding the complete removal of the lesion. Overall complication rate was really low. In the case of partially resected recurrent solitary fibrous tumor, a mild ptosis was observed, probably related to the strict adhesion of the lesion to the levator palpebrae superior muscle complex. Based on this surgical experience, we do not advice the use of such minimally invasive approach in case of recurrent vascular tumors.

Among the advantages of this technique, we strongly believe that the endoscopic visualization, that is able to bring light close to the structures, offers a really outstanding identification of the orbital details. New technologies, including also 3D, will probably increase the ability to manage this kind of lesions ${ }^{(14,19)}$. The avoidance of bony work, the short trajectory to the target and the possibility to work with the same principles of micro-neurosurgery make such approach, at least in our opinion, worthy of attention. Obviously, when proposing such transorbital approaches the advantages must be clearly balanced to the potential risks, since some orbital complications could provoke catastrophic effects to the patient ${ }^{(20)}$. And we are perfectly conscious that 
the concept of minimally invasiveness does not depend on the entry wound size, but on the reduced impact that the procedure has on the patient's quality of life. In this respect, the surgical strategy should be decided accordingly with the patient, after a careful and honest discussion. Anyway, from a functional viewpoint, we consider promising the preliminary experience herein presented, given the fact all the patients treated have been satisfied about the procedure.

One critical point is related to the learning curve necessary to get enough skill to manage such lesions. We feel that, especially for orbital apex lesions, the procedure should be attempted in very selected cases by experienced teams able to convert the procedure in a more conventional route and able to face even severe complications. Furthermore, we do not recommend the application of such an approach for recurrent vascular tumors. As a matter of fact, similarly to other minimally invasive approach, the most critical aspect in transorbital endoscopic procedures to the intraorbital region is to obtain both an adequate target exposure and enough room for working.

Finally, since most orbital and skull base surgeons are more confident with the traditional transcranial approaches, one does not expect broad acceptance of this transorbital route. Nevertheless, the endoscopic assisted superior eyelid transorbital approach should be considered as a possible alternative that can be applied in selected cases. In this respect, we do not want to propose such an approach as the gold standard for every intraorbital procedure but we would simply describe our ongoing experience, adding our cases to the current body of data on this topic. We are perfectly aware that larger case series, possibly from different groups worldwide, are needed in order to understand the real applicability of such an approach.

\section{Acknowledgements}

No sponsors or grants were involved in the paper.

\section{Authorship contribution}

ID: conception and design of the study; contribution on drafting the article; final approval of the version to be published. PC: conception and design of the study; final approval of the version to be published. MTZ: conception and design of the study; contribution on drafting the article; final approval of the version to be published. GF: acquisition of data; final approval of the version to be published. DL: revised the manuscript critically for important intellectual content; final approval of the version to be published. PB: analysis and interpretation of data; final approval of the version to be published. SSF: conception and design of the study; revised the manuscript critically for important intellectual content; final approval of the version to be published.

\section{Conflict of interest}

All the authors certify that they have no conflict of interest or financial relationship with any entity mentioned in the paper.

\section{References}

1. Bradoo R, Potdar N, Joshi A, Shah K, Modi R, Shinde C. Transcutaneous Endoscopic Orbital Surgery: A Less Morbid Alternative to Lateral Orbitotomy. Orbit 2015; 34(1): 1-5.

2. Castelnuovo P, Dallan I, Locatelli D, et al. Endoscopic endonasal intraorbital surgery: our experience with 16 cases. Eur Arch Otorhinolaryngol 2012; 269: 1929-35.

3. Castelnuovo P, Turri-Zanoni M, Battaglia P, Locatelli D, Dallan I. Endoscopic Endonasal Management of Orbital Pathologies. Neurosurg Clin N Am 2015; 26(3):463-72.

4. Dallan I, Castelnuovo P, de Notaris $M$, et al. Endoscopic endonasal anatomy of superior orbital fissure and orbital apex regions: critical considerations for clinical applications. Eur Arch Otorhinolaryngol 2013; 270(5):1643-9.

5. Norris JL, Cleasby GW. Endoscopic Orbital Surgery. Am J Ophthalmol 1981; 91(2): 24952.

6. Rivkin MA, Turtz AR, Morgenstern KE. Transorbital endoscopic removal of posterior lateral orbital mass. Laryngoscope 2013; 123(12): 3001-4

7. Dallan I, Locatelli D, Turri-Zanoni M, et al Transorbital endoscopic assisted resection of a superior orbital fissure cavernous haemangioma: a technical case report. Eur
Arch Otorhinolaryngol 2015; DOI 10.1007/ s00405-015-3556-2.

8. Robinson K, Gatehouse S, Browning GG Measuring patient benefit from otorhinolaryngological surgery and therapy. Ann Otol Rhinol Laryngol 1996; 105(6):415-22.

9. Hendry J, Chin A, Swan I, Akeroyd MA, Browning GG. The Glasgow Benefit Inventory: A systematic review of the use and value of an Otorhinolaryngological generic Patient Recorded Outcome Measure [PROM]. Clin Otolaryngol 2015; doi: 10.1111/coa.12518.

10. Smith HB, Jyothi SB, Mahroo OA, Shams PN, Sira M, Dey S, Adewoyin T, Cheung VT, Jones CA. Patient-reported benefit from oculoplastic surgery. Eye (Lond) 2012; 26(11):1418-23

11. Dallan I, Castelnuovo P, Sellari-Franceschini S, Locatelli D. Endoscopic orbital and transorbital approaches. Tuttlingen, Germany: EndoPress GmbH, 2015. ISBN 978-3-89756217-2.

12. Khan AM, Varvares MA. Traditional approaches to the orbit. Otolaryngol Clin N Am 2006; 39: 895-909.

13. Rootman J. Orbital Surgery. A conceptual approach. 2nd edition. Philadelphia, USA Wolter Kluwer Lippincott Williams \& Wilkins, 2014
14. Roth J, Fraser JF, Singh A, Bernardo A, Anand VK, Schwartz TH. Surgical approached to the orbital apex: comparison of endoscopic endonasal and transcranial approaches using a novel 3D Endoscope. Orbit 2011; 30(1): 43-8.

15. Lew $H$, Rootman DB, Nassiri N, Goh A, Goldberg RA. Transorbital Approach Without Craniotomy to orbital tumors with extradural Intracranial Extension. Orbit 2014; 33(5): 343-51.

16. Dallan I, Castelnuovo P, Locatelli D, et al. Multiportal Combined Transorbital Transnasal Endoscopic Approach for the Management of Selected Skull Base Lesions: Preliminary Experience. World Neurosurg 2015; 84(1):97-107.

17. Moe K, Bergeron CM, Ellenbogen RG. Transorbital neuroendoscopic surgery. Neurosurgery 2010; 67(3 Suppl Operative): ons16-28.

18. Sellari-Franceschini S, Berrettini S, Santoro A, et al. Orbital decompression in Graves ophthalmopathy by medial and lateral wall removal. Otolaryngol Head Neck Surg 2005; 133(2):185-9.

19. Castelnuovo P, Battaglia P, Bignami M, et al. Endoscopic transnasal resection of anterior skull base malignancy with a novel 3D endoscope and neuronavigation. Acta 
Otorhinolaryngol Ital 2012; 32(3):189-91.

20. Sonig A, Nanda A. Transorbital approach to the Anterior Cranial Skull Base. World Neurosurg 2013; 80 (6): 810-2.
Mario Turri-Zanoni, MD

Unit of Otorhinolaryngology

Azienda Ospedaliero-Universitaria

Ospedale di Circolo e Fondazione

Macchi

Via Guicciardini 9

Varese

Italy
Tel: +39-(0)332-393278

Fax: +39-(0)332-393279

E-mail: tzmario@inwind.it

\section{ADVERTISEMENT}
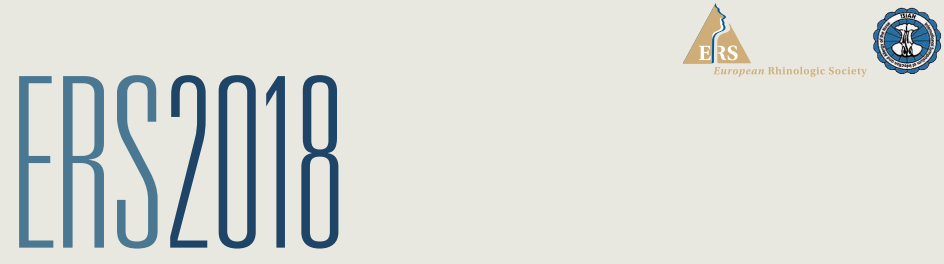

$27^{\text {TH }}$ CONGRESS OF THE

EUROPEAN RHINOLOGIC SOCIETY

in conjunction with

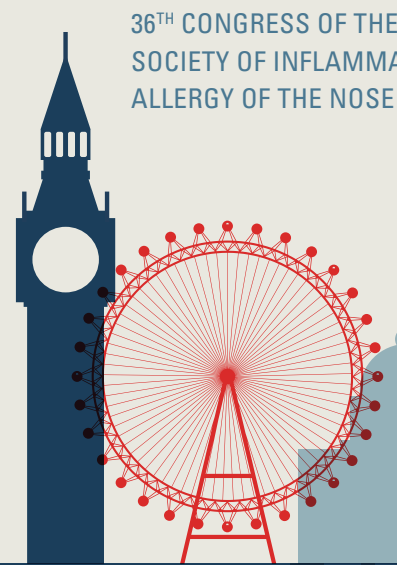

$18^{\text {TH }}$ CONGRESS OF THE

INTERNATIONAL RHINOLOGIC SOCIETY (IRS)

\section{(ISIAN)}

SOCIETY (IRS)

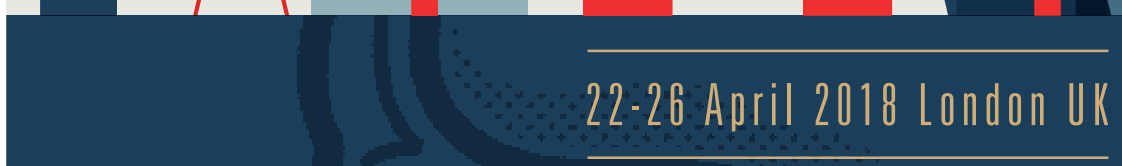

www.ers-isian $2018.00 \mathrm{~m}$

RHINOLOGY 2018

WHER

ART \& SCIENCE

MEET 